\title{
Effects of Thyroid Hormone on the Cardiovascular System
}

\author{
Serafino Fazio, ${ }^{*}$ Emiliano A. Palmieri, ${ }^{*}$ Gaetano Lombardi, ${ }^{\dagger}$ and \\ BernadetTe Biondi ${ }^{\dagger}$ \\ *Department of Clinical Medicine and Cardiovascular Sciences; ${ }^{\dagger}$ Department of Clinical and \\ Molecular Endocrinology and Oncology, University of Naples "Federico II" School of Medicine, \\ 80131, Naples, Italy
}

\begin{abstract}
Increased or reduced action of thyroid hormone on certain molecular pathways in the heart and vasculature causes relevant cardiovascular derangements. It is well established that overt hyperthyroidism induces a hyperdynamic cardiovascular state (high cardiac output with low systemic vascular resistance), which is associated with a faster heart rate, enhanced left ventricular (LV) systolic and diastolic function, and increased prevalence of supraventricular tachyarrhythmias - namely, atrial fibrillation - whereas overt hypothyroidism is characterized by the opposite changes. However, whether changes in cardiac performance associated with overt thyroid dysfunction are due mainly to alterations of myocardial contractility or to loading conditions remains unclear. Extensive evidence indicates that the cardiovascular system responds to the minimal but persistent changes in circulating thyroid hormone levels, which are typical of individuals with subclinical thyroid dysfunction. Subclinical hyperthyroidism is associated with increased heart rate, atrial arrhythmias, increased LV mass, impaired ventricular relaxation, reduced exercise performance, and increased risk of cardiovascular mortality. Subclinical hypothyroidism is associated with impaired LV diastolic function and subtle systolic dysfunction and an enhanced risk for atherosclerosis and myocardial infarction. Because all cardiovascular abnormalities are reversed by restoration of euthyroidism ("subclinical hypothyroidism") or blunted by $\beta$-blockade and L-thyroxine (L-T4) dose tailoring ("subclinical hyperthyroidism"), timely treatment is advisable in an attempt to avoid adverse cardiovascular effects. Interestingly, some data indicate that patients with acute and chronic cardiovascular disorders and those undergoing cardiac surgery may have altered peripheral thyroid hormone metabolism that, in turn, may contribute to altered cardiac function. Preliminary clinical investigations suggest that administration of thyroid hormone or its analogue 3,5-diiodothyropropionic acid greatly benefits these patients, highlighting the potential role of thyroid hormone treatment in patients with acute and chronic cardiovascular disease.
\end{abstract}

\section{Introduction}

Thyroid hormone has relevant effects on the cardiovascular system (Klein and Ojamaa, 2001). Many symptoms and signs recognized in patients with overt hyperthyroidism and hypothyroidism are due to the increased or reduced action of thyroid hormone on the heart and the vascular system, respectively, and the related hemodynamic derangements (Table I). In recent decades, it has emerged 
TABLE I

Hemodynamics and Cardiac Function in Overt Thyroid Dysfunction

\begin{tabular}{lccc}
\hline Parameter & Normal values & Hyperthyroidism & Hypothyroidism \\
\hline Blood volume (\% of normal value) & 100 & 105.5 & 84.5 \\
Heart rate (bpm) & $72-84$ & $88-130$ & $60-80$ \\
Cardiac output (L/min) & $4.0-6.0$ & $>7.0$ & $<4.5$ \\
Systemic vascular resistance (dyn·sec/cm ${ }^{-5}$ ) & $1500-1700$ & $700-1200$ & $2100-2700$ \\
& & & $\leq 60$ \\
Left ventricular ejection fraction (\%) & $>50$ & $>65$ & $>80$ \\
Isovolumic relaxation time (msec) & $60-80$ & $25-40$ & \\
\end{tabular}

[Reprinted with permission from Klein I, Ojamaa K 2001 Thyroid hormone and the cardiovascular system. N Engl J Med 344:501-509. Copyright (C) 2001 Massachusetts Medical Society.]

that subclinical thyroid dysfunction may affect the cardiovascular system, which may increase cardiovascular risk. It is becoming increasingly apparent that acute and chronic cardiovascular disease may alter thyroid hormone metabolism and contribute to cardiovascular impairment. This chapter will provide an overview of the basic mechanisms underlying the effects of thyroid hormone on the cardiovascular system and their clinical correlates, then address the potential benefit of thyroid hormone treatment in patients with cardiovascular disorders.

\section{Cellular Effects of Thyroid Hormone on the Cardiovascular System}

Most of the molecular and cellular mechanisms responsible for the cardiovascular effects of thyroid hormone have been clarified. As shown in Figure 1, thyroid hormone may exert both genomic and nongenomic effects on cardiac myocytes. The genomic effects of thyroid hormone are mediated by the transcriptional activation or repression of specific target genes that encode both structural and functional proteins (Dillmann, 1990). This process begins with the entry of triiodothyronine (T3), the biologically active thyroid hormone, into the cardiomyocyte through specific transport proteins located within the cell membrane (Everts et al., 1996). To date, there is no clear evidence of a biologically relevant conversion of thyroxine (T4) to T3 in cardiomyocytes (Everts et al., 1996). Once in the cardiomyocyte, T3 enters the nucleus and interacts with 


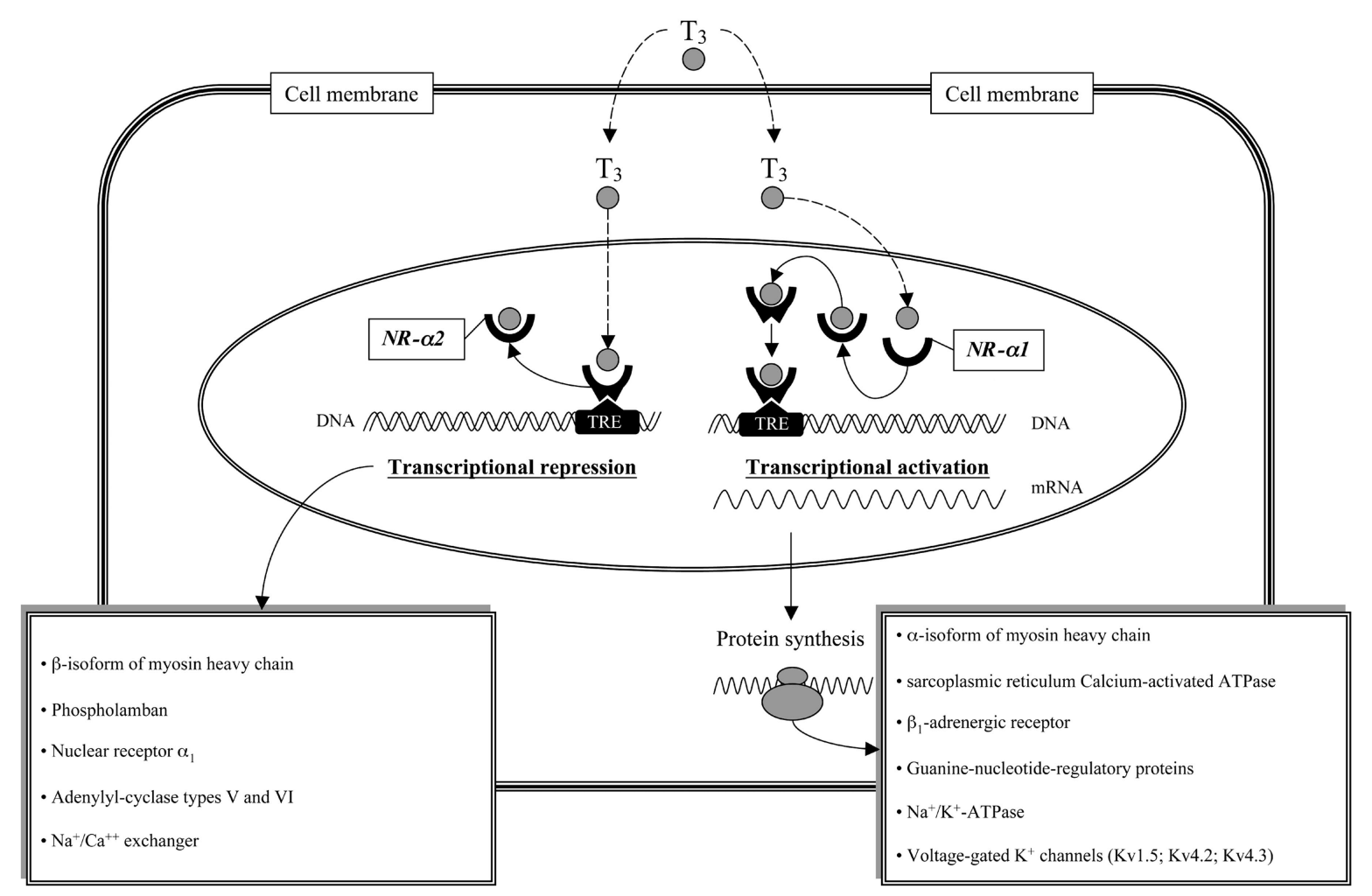

FIG. 1. Genomic effects of thyroid hormone (T3) on cardiomyocytes. NR, triiodothyronine nuclear receptor; TRE, thyroid hormone responsive element (see text for details) 
specific transcriptional activators (nuclear receptor $\alpha 1$ ) or repressors (nuclear receptor $\alpha 2$ ). Occupancy of these receptors by T3, in combination with recruited cofactors, allows the thyroid hormone-receptor complex to bind (nuclear receptor $\alpha-1$ ) or release (nuclear receptor $\alpha$-2) specific sequences of DNA (thyroidresponsive elements) that, in turn, by acting as cis- or trans-regulators, modify the rate of transcription of specific target genes (Brent, 1994).

Among various proteins whose expression is modulated at transcriptional level (Figure 1), the most-extensively characterized are myosin heavy chains (Morkin, 1993; Ojamaa et al., 1996b) and the sarcoplasmic reticulum protein involved in the regulation of intracellular calcium handling, namely, calciumactivated ATPase and its inhibitory cofactor, phospholamban (Dillmann, 1990; Kiss et al., 1994). Many studies in vitro and in experimental rats incontrovertibly show that thyroid hormone upregulates the expression of the $\alpha$-isoform of the myosin heavy chain in cardiomyocytes, while it downregulates the $\beta$-isoform (Morkin, 1993; Ojamaa et al. 1996b). There is some evidence that this regulation also occurs in humans (Ladenson et al., 1992). However, the magnitude of this phenomenon is certainly less pronounced than in rodents - a finding that fuels uncertainties about the functional correlate of this molecular effect. In humans, the $\beta$-isoform of the myosin heavy chain is more prevalent than the $\alpha$-isoform (Magner et al., 1988; Ladenson et al., 1992) and the ratio is only marginally modified by thyroid hormone (Ladenson et al., 1992).

In contrast, several lines of evidence suggest that some abnormalities of cardiac function in patients with thyroid dysfunction directly reflect the effects of thyroid hormone on calcium-activated ATPase and phospholamban, which are involved primarily in the regulation of systodiastolic calcium concentrations in cardiomyocytes (Dillmann, 1990; Kiss et al., 1994). Sarcoplasmic reticulum calcium-activated ATPase is responsible for the rate of calcium reuptake into the lumen of the sarcoplasmic reticulum during diastole that, in turn, is a major determinant of the velocity of myocardial relaxation after contraction (Dillmann, 1990; Kiss et al., 1994). However, the performance of sarcoplasmic reticulum calcium-activated ATPase is influenced by the level of expression of phospholamban: the higher the phospholamban expression, the lower the sarcoplasmic reticulum calcium-activated ATPase activity (Kiss et al., 1994). In this regard, it has been extensively demonstrated that thyroid hormone upregulates expression of the sarcoplasmic reticulum calcium-activated ATPase and downregulates expression of phospholamban, thereby enhancing myocardial relaxation (Dillmann, 1990; Kiss et al., 1994). Indeed, the improved calcium reuptake during diastole may favorably affect myocardial contractility. In fact, the greater reduction in cytoplasmatic concentration of calcium at end-diastole increases the magnitude of the systolic transient of calcium that, in turn, augments its availability for activation of tropo-myosin units. In fact, in phospholambandeficient mice, cardiac contractility was found to be increased, with no further 
increase after thyroid hormone treatment (Kiss et al., 1998). This finding strongly supports the key role of sarcoplasmic reticulum proteins and their effects on intracellular calcium handling in thyroid hormone-mediated changes in systodiastolic cardiac function in patients with thyroid dysfunction. In this context, it is important to recognize that thyroid hormone also modifies the expression of other ion channels, such as $\mathrm{Na}^{+} / \mathrm{K}^{+}$-activated ATPase, $\mathrm{Na}^{+} / \mathrm{Ca}^{++}$exchanger, and some voltage-gated $\mathrm{K}^{+}$channels $(\mathrm{Kv} 1.5, \mathrm{Kv} 4.2$, Kv4.3), thereby coordinating the electrochemical and mechanical responses of the myocardium (Gick et al., 1990; Ojamaa et al., 1999).

In addition to these genomic effects, thyroid hormone produces changes in cardiac inotropism and chronotropism more rapidly than would be expected from regulation of gene expression, which usually take minutes to hours to be phenotypically and functionally appreciable. This calls into question the involvement of nongenomic mechanisms (Davis and Davis, 1993; Walker et al., 1994). Some evidence indicates that thyroid hormone promotes the acute phosphorylation of phospholamban and that this action attenuates the inhibitory effect of phospholamban on sarcoplasmic reticulum calcium-activated ATPase (Ojamaa et al., 2002). Interestingly, the fact that this process is mediated at least in part by the activation of intracellular kinase pathways involved in signal transduction of the adrenergic stimulus (Ojamaa et al., 2002) may help to explain functional analogies between the cardiovascular effects of thyroid hormone and those promoted by the adrenergic system (Levey and Klein, 1990). Indeed, although most of the cardiovascular manifestations associated with hyperthyroidism and hypothyroidism mimic a condition of increased and reduced adrenergic activity, respectively, the sensitivity of the cardiovascular system to adrenergic stimulation does not seem to be substantially altered in these conditions (Hoit et al., 1997; Ojamaa et al., 2000).

Thyroid hormone also exerts an important effect on the vascular system. It acutely reduces peripheral vascular resistance by promoting relaxation in vascular smooth-muscle cells (Klemperer et al., 1995; Ojamaa et al., 1996a; Park et al., 1997). A single study has reported that chronic thyroid hormone excess exerts profound effects on vascular reactivity by improving both endothelium-dependent and -independent mechanisms (Napoli et al., 2001).

\section{Overt Hyperthyroidism}

Palpitation is one of the most-common symptoms associated with overt hyperthyroidism (Nordyke et al., 1988). Continuous, ambulatory, 24-hour electrocardiogram (ECG) monitoring characteristically demonstrates that heart rate is constantly increased during the day and exaggerated in response to exercise, although its circadian rhythm usually is preserved (von Olshausen et al., 1989; Cacciatori et al., 1996). Analysis of heart rate variability reveals sympatho-vagal 
unbalancing with a relative increase in sympathetic tone (Cacciatori et al., 1996). In this respect, although $\beta$-adrenergic blockade usually attenuates tachycardia in patients with overt hyperthyroidism, heart rates remain slightly higher, in comparison with euthyroid controls. This supports the notion that thyroid hormone is able to directly affect sinus node firing (Sun et al., 2001).

About $5-10 \%$ of overt hyperthyroid patients have atrial fibrillation, which may be the presenting problem (Sawin et al., 1994; Auer et al., 2001). Atrial fibrillation usually reverts to sinus rhythm with achievement of euthyroidism (Nakazawa et al., 1982), the reversion rate decreasing with age and duration of arrhythmia (Nakazawa et al., 1982; Nordyke et al., 1988). Therefore, achievement of the euthyroid state should be the primary treatment strategy of atrial fibrillation associated with overt hyperthyroidism. $\beta$-adrenergic blockade may be used effectively to control the ventricular rate. In all instances, electrical or pharmacological cardioversion should be an option only after achievement of euthyroidism. In this context, it remains controversial whether overt hyperthyroid patients with atrial fibrillation should receive anticoagulant therapy. In general, the risk of bleeding with anticoagulant therapy always should be weighed against the risk of systemic embolization (Gilligan et al., 1996) and the decision made on a case-by-case basis. In general, it would be appropriate to administer anticoagulant agents to older patients with known or suspected heart disease or with atrial fibrillation of longer duration (Petersen and Hansen, 1988; Gilligan et al., 1996).

Systolic arterial pressure is almost invariably increased and diastolic arterial pressure decreased in subjects with overt hyperthyroidism, so that pulse pressure is characteristically wider and mean arterial pressure is only marginally decreased (Graettinger et al., 1959; Theilen and Wilson, 1967; DeGroot and Leonard, 1970). These hemodynamic changes are associated with a remarkable increase in cardiac output and a notable reduction in peripheral vascular resistance, thereby resulting in the classic hyperdynamic cardiovascular state (Graettinger et al., 1959; Theilen and Wilson, 1967; DeGroot and Leonard, 1970).

The main determinants of increased at-rest left ventricular (LV) performance in patients with overt hyperthyroidism have not been definitively established (Biondi et al., 2002a). The high cardiac output state results from a remarkably faster heart rate and a slightly augmented stroke volume that, in turn, is associated with normal or marginally enlarged LV end-diastolic size and normal or marginally decreased LV end-systolic size (Biondi et al., 2002a). As a result, LV ejection fraction, an index of overall systolic chamber function, characteristically is increased in overt hyperthyroid subjects (Biondi et al., 2002a). Whether this process is sustained mainly by a true enhancement of myocardial contractility or by the interaction of hemodynamic factors is unclear (Biondi et al., 2002a). Studies by Merillon and colleagues (1981) and by Feldman and coworkers (1986) are emblematic of the controversy surrounding this argument. 
Merillon and coworkers (1981) assessed LV function in seven overt thyrotoxic subjects by cardiac catheterization, compared with 11 euthyroid controls atrially paced at a near-identical heart rate. They found no differences between the two groups in such parameters of contractile performance as LV ejection fraction, rate of rise of LV pressure as a proportion of the total pressure, velocity of circumferential fiber shortening, and ratio of LV end-systolic pressure to end-systolic volume. Conversely, it was noted that atrial pacing, but not hyperthyroidism, was accompanied by a marked reduction in both end-diastolic volume and pressure and by a significant increase in systemic vascular resistance and mean aortic pressure. As expected, cardiac performance was not increased in atrially paced subjects. Although atrial pacing and hyperthyroidism are not strictly comparable (acute vs. chronic condition), the authors concluded that there was no realistic increase in the true level of myocardial contractility independent of changes in heart rate and preload in human hyperthyroidism.

Feldman and colleagues (1986) studied LV function in 11 hyperthyroid patients by means of echocardiography and in 11 age-matched normal subjects. They found no differences between the two groups in LV end-diastolic diameter or in end-systolic meridional wall stress. Differently, the rate-corrected mean velocity of circumferential fiber shortening (a measure of $\mathrm{LV}$ function claimed to be independent of preload and heart rate) was much higher in hyperthyroid patients. As a result, when LV end-systolic wall stress was related to the rate-corrected velocity of fiber shortening, the values of hyperthyroid patients were above the mean regression line for normal subjects, reflecting the presence of an increased contractile state. The authors, however, did not consider that the normal end-diastolic dimension, despite the augmented heart rate in their patients, corresponded to an effective increase in preload, given the inverse relationship between the two variables. Furthermore, the noninvasive method of assessing myocardial contractility by relating the rate-corrected circumferential fiber-shortening velocity to meridional LV end-systolic wall stress may overestimate myocardial performance in pathophysiological states characterized by simultaneous increases in preload and heart rate.

Based on these remarks, it may be assumed that the notably faster heart rate in hyperthyroid patients masks the actual increase in cardiac preload, leading to an underestimation of the extent to which the Frank-Starling mechanism contributes to improving cardiac performance (Biondi et al., 2002a). Indeed, there is evidence that cardiac preload is increased in overt hyperthyroidism. Some studies have demonstrated clearly that blood volume is enlarged in patients with overt hyperthyroidism (Gibson and Harris, 1939; Anthonisen et al., 1960). Other studies showed that the renin-angiotensin-aldosterone system is activated in hyperthyroid patients (Resnick and Laragh, 1982). In addition, thyroid hormone has been shown to upregulate erythropoietin secretion and, in turn, red blood cell mass, which may also contribute to the increase in total blood volume (Gibson 
and Harris, 1939; Graettinger et al., 1959; Klein and Levey, 1984). Moreover, the analysis of LV diastolic function in different investigations has almost invariably revealed an increase in indices of early LV filling and a faster LV relaxation independent of the effect of heart rate (Lewis et al., 1979; Friedman et al., 1982; Mintz et al., 1991; Kahaly et al., 1999). This pattern of diastolic function is consistent with a greater venous return and enhanced ventricular suction, suggesting that the improvement in diastolic function would allow the increased venous return to be accommodated without relevant changes in filling pressure. This interpretation is supported by the observation of comparable values of LV end-diastolic volume and pressure in hyperthyroid patients and normal subjects (Merillon et al., 1981).

It is, therefore, conceivable that the hyperthyroid heart increases its performance through the advantageous modulation of hemodynamic loads, rather than through recourse to its inotropic reserve (Biondi et al., 2002a). In this regard, it is important to underline that the mechanisms that utilize myocardial contractility involve an ever and necessarily greater myocardial metabolic demand. On the contrary, recourse to the hemodynamic loads to improve cardiac performance is an energetically favorable mechanism. Indeed, recourse to the latter mechanism optimizes the cardiac mechanic-energetic utilization in a condition such as hyperthyroidism, in which a clear increase of myocardial energetic consumption is already present (Bengel et al., 2000).

The complicated and delicate interaction between the different factors determining cardiac function in the patient with overt hyperthyroidism may explain, at least in part, two clinical observations. The first, and more frequent, is reduced exercise tolerance (Kahaly et al., 1998,1999); the second - lessfrequently encountered than in the past - is development of congestive heart failure (CHF) (Magner et al., 1988). On the one hand, reduced exercise tolerance of hyperthyroid patients may result from their reduced cardiovascular reserve (Kahaly et al., 1998,1999). In fact, the mechanisms used by the cardiovascular system during exercise are almost largely used at rest. On the other hand, CHF may be precipitated by the occurrence of atrial fibrillation. The loss of atrial contribution to ventricular filling and the reduced diastolic time may severely compromise diastolic dynamics, increasing end-diastolic pressure and promoting systemic congestion. Occasionally, CHF may develop as a result of the so-called "rate-related cardiomyopathy" (Magner et al., 1988).

\section{Subclinical Hyperthyroidism}

Subclinical hyperthyroidism is characterized by subnormal or suppressed thyrotropin (TSH) serum levels in the presence of circulating thyroid hormones in the normal range for the general population (Biondi et al., 2002c). It may be due to an intrinsic pathology of the thyroid gland (endogenous subclinical 
hyperthyroidism) but, more often, is the consequence of suppressive or replacement L-thyroxine (L-T4) therapy (exogenous subclinical hyperthyroidism) (Biondi et al., 2002c). Exogenous subclinical hyperthyroidism is the condition more-frequently seen in clinical practice (Biondi et al., 2002c).

Over past decades, a number of studies have investigated the effects of subclinical hyperthyroidism on the heart, showing that this condition may be associated with important abnormalities of cardiac structure and function (Biondi et al., 2002c). The more-consistent abnormalities found in patients with subclinical hyperthyroidism are increased heart rate and prevalence of supraventricular arrhythmias and enhanced LV mass (Biondi et al., 1993,1994,1996,1999b,2000; Fazio et al., 1995; Ching et al., 1996; Shapiro et al., 1997; Mercuro et al., 2000). The latter feature often is associated with slightly enhanced systolic function and almost always with impaired diastolic function due to slowed myocardial relaxation (Biondi et al., 1993,1994,1996,1999b,2000; Fazio et al., 1995; Ching et al., 1996; Shapiro et al., 1997; Mercuro et al., 2000). The increase in LV mass is due to increased wall thickness without changes of cavity dimension ("concentric remodeling"). It rarely corresponds to an actual LV hypertrophy and is related to the duration of subclinical hyperthyroidism rather than to circulating thyroid hormone levels. The mechanism responsible for the increase in LV mass has not been completely clarified. In general, it is assumed to develop in response to a chronic hemodynamic overload due to the mild hyperkinetic cardiovascular state (Klein, 1988; Fazio et al., 1995). In fact, as happens with classic models of overload-induced cardiac hypertrophy, the increase of LV mass observed in patients with subclinical hyperthyroidism is associated with slowed myocardial relaxation and impaired ventricular filling. It has been suggested that this diastolic dysfunction results from altered intracellular calcium handling due to reduced expression of sarcoplasmic reticulum calcium ATPase and/or increased expression of phospholamban, with the consequent delayed sarcoplasmic reuptake of calcium. However, this view would contrast with the well-known effects of thyroid hormone on such genes (Dillmann, 1990; Kiss et al., 1994). Therefore, it may be hypothesized that, in the long-term, the effects of chronically increased cardiac workload on calcium metabolism would prevail on those promoted by thyroid hormone. Be that as it may, abnormalities of LV morphology and function promptly normalize with achievement of euthyroidism and are effectively attenuated by $\beta$-blocking drugs (Biondi et al., 1994,1995,1999b, 2000). This supports the concept that cardiac involvement in subclinical hyperthyroidism is reversible and mostly determined by functional mechanisms.

Importantly, compelling evidence exists that subclinical hyperthyroidism is associated with increased cardiovascular mortality (Parle et al., 2001). Although the mechanism responsible for this association remains obscure, several factors may contribute to this phenomenon (Biondi et al., 2002b). There are indications that patients with subclinical hyperthyroidism, particularly the elderly, have an 
increased risk of atrial fibrillation (Sawin et al., 1994; Auer et al., 2001), which may enhance the incidence of thromboembolic events (Petersen and Hansen, 1988; Ladenson, 1993). It has been shown that the increase of LV mass per se, even in the absence of a clear LV hypertrophy, and of heart rate are associated with an increased risk of sudden death (Haider et al., 1998; Greenland et al., 1999). Moreover, it is well-recognized that diastolic dysfunction may precede development of more-severe LV dysfunction. Indeed, especially in the elderly, it may precipitate cardiac decompensation and CHF. Therefore, the current opinion is to avoid or correct subclinical hyperthyroidism in all patients affected with benign thyroid disease (Biondi et al., 2002c). On the contrary, when subclinical hyperthyroidism is a therapeutic indication (e.g., in patients with differentiated thyroid cancer), L-T4 should be administered at the lowest dose sufficient to achieve a stable TSH suppression, eventually associated with chronic $\beta$-blockade (Biondi et al., 2002c). Contextually, subclinical hyperthyroidism should be suspected in all subjects with a history of atrial fibrillation, especially in the elderly and in those with underlying cardiac disease who complain of worsening of angina pectoris or cardiac decompensation.

\section{Overt Hypothyroidism}

The cardiovascular effects of thyroid hormone deficiency are opposite to those caused by thyroid hormone excess. However, the clinical presentation of overt hypothyroidism is not obvious and most patients have few symptoms and signs (Klein and Ojamaa, 2000). Bradycardia and systemic hypertension, with narrow pulse pressure and slightly increased mean arterial pressure, and some degree of exercise impairment are the most-common findings in patients with overt hypothyroidism (McAllister et al., 1995; Klein and Ojamaa, 2000).

Many patients with overt hypothyroidism have abnormal standard ECG, including QT interval lengthening and flattening or inversion of the $\mathrm{T}$ wave (Fredlund and Olsson, 1983; Klein and Ojamaa, 2000), which reflects the prolonged cardiac action potential (Ojamaa et al., 1999). In addition, overt hypothyroid patients are more prone to ventricular arrhythmias, particularly in the presence of an underlying ischemic heart disease, due to increased electrical dispersion in the myocardium (Fredlund and Olsson, 1983; Klein and Ojamaa, 2000).

The prevalence of systemic hypertension is nearly three-fold higher in patients with overt hyperthyroidism than in euthyroid subjects. In addition, in patients with systemic hypertension, overt hypothyroidism is associated with higher blood pressure (Endo et al., 1979; Saito et al., 1983; Streeten et al., 1988; Klein, 1989; Fletcher and Weetman, 1998; Fommei and Iervasi, 2002). Two factors contribute to systemic hypertension in overt hypothyroidism. The first, and certainly the most-widely recognized, is the remarkable increase in periph- 
eral vascular resistance (Klein and Ojamaa, 2000). The second, and morerecently documented, is the increase in arterial stiffness, which likely results from myxedema of the arterial wall (Dernellis and Panaretou, 2002; Obuobie et al., 2002). In general, systemic hypertension associated with overt hypothyroidism is poorly controlled by conventional treatments, whereas it promptly improves with achievement of euthyroidism (Dernellis and Panaretou, 2002). This finding would encourage the routine assessment of thyroid function in all patients with preexisting systemic hypertension that becomes resistant to pharmacological treatment.

The most-consistent cardiac abnormality recognized in patients with overt hypothyroidism is impairment of $\mathrm{LV}$ diastolic function, which is characterized by slowed myocardial relaxation and impaired early ventricular filling (Crowley et al., 1977; Wieshammer et al., 1989). LV systolic function usually is only marginally subnormal, as demonstrated by slightly reduced values of ejection fraction and stroke volume (Crowley et al., 1977; Wieshammer et al., 1989). On the one hand, the reduced cardiac preload, in combination with bradycardia and slightly depressed myocardial contractility, accounts for a subnormal cardiac output in overt hypothyroidism (Crowley et al., 1977; Wieshammer et al., 1989). On the other hand, the lower cardiac performance and the abnormalities in peripheral and proximal vascular function may contribute to the poor exercise tolerance in overt hypothyroidism (McAllister et al., 1995).

Occasionally, cardiac function may be further compromised by the development of pericardial effusion, which occurs with severe, long-standing overt hypothyroidism (Ladenson et al., 1992). In addition, overt hypothyroidism may be associated with some increase in LV mass. However, as shown by necropsy and ultrasound investigations, the increase in LV mass does not correspond to myocardial hypertrophy sensu strictu but rather to interstitial myxedema (Aber, 1964). By increasing wall stiffness, cardiac myxedema may further compromise LV mechanics, contributing to reduced cardiac output.

In this context, it is important to recall that although overt hypothyroidism is associated with a lower myocardial oxygen demand, myocardial mechanical work efficiency is worse than in euthyroid controls and improves with achievement of euthyroidism (Bengel et al., 2000). The increase in peripheral vascular resistance and arterial stiffness in overt hypothyroidism contributes to increased cardiac afterload, one of the major factors determining myocardial oxygen consumption (Bengel et al., 2000). The disproportionate increase in myocardial oxygen uptake with respect to the level of cardiac performance may, therefore, explain at least in part why overt hypothyroidism may precipitate or worsen angina in patients with suspected or known ischemic heart disease (Keating et al., 1960) and why some of these patients have an improvement in anginal symptoms after thyroid hormone replacement is initiated. 
Overt hypothyroidism may be particularly hazardous in the elderly, independent of the presence of underlying cardiovascular disease. Aging is accompanied by the development of cardiac hypertrophy and interstitial fibrosis, which may be responsible per se for diastolic dysfunction and reduced cardiovascular performance. Therefore, the onset of overt hypothyroidism in this vulnerable population occasionally may precipitate cardiac decompensation and CHF. In a single study, it was estimated that approximately $30-50 \%$ of elderly subjects with heart failure have normal values of ejection fraction (diastolic heart failure) (McDermott et al., 1995). Noteworthy, diastolic heart failure was strongly associated with hypothyroidism and was more prevalent in women (McDermott et al., 1995). Therefore, thyroid function should be routinely assessed in older patients with newly diagnosed or worsening heart failure.

\section{Subclinical Hypothyroidism}

Subclinical hypothyroidism (SH), defined by elevated serum TSH level in the presence of normal levels of free thyroid hormones, is common in the adult population, especially among women above 60 years of age (Tunbridge et al., 1977; Canaris et al., 2000). Up to two thirds of patients have serum TSH between 5-10 mU/L and thyroid autoantibodies (Tunbridge et al., 1977; Canaris et al., 2000). Almost half of these individuals may progress to overt thyroid failure (Vanderpump et al., 1995; Huber et al., 2002).

Striking evidence indicates that elevated TSH levels in SH patients do not reflect pituitary compensation to maintain euthyroidism but mild tissue hypothyroidism sensu strictu (Andersen et al., 2002). Several changes in metabolic and organ function indexes have been reported in most clinical investigations of patients with persistent SH (Biondi et al., 2002c). Deviation from normality progressively increases with serum TSH level ("dosage effect" phenomenon) (Lekakis et al., 1997; Bindels et al., 1999; Faber et al., 2002).

In general, resting heart rate and blood pressure are normal in SH subjects (Biondi et al., 1999a; Monzani et al., 2001; Di Bello et al., 2002; Vitale et al., 2002). However, significant hypofunctional abnormalities in the parasympathetic nervous system and an increased prevalence of systemic hypertension have been reported in patients with SH (Kahaly, 2000; Luboshitzky et al., 2002).

The most-consistent cardiac abnormality recognized in SH patients is LV diastolic dysfunction, characterized by slowed myocardial relaxation and impaired early ventricular filling, both at rest and with exercise (Biondi et al., 1999a; Monzani et al., 2001; Di Bello et al., 2002; Vitale et al., 2002; Brenta et al., 2003). Often, this is associated with a variable impairment in LV systolic function at rest (Biondi et al., 1999a; Monzani et al., 2001; Di Bello et al., 2002; Vitale et al., 2002), which becomes more consistent on exercise (Foldes et al., 1987; Kahaly, 2000; Brenta et al., 2003). In a comprehensive study of exercise 
capacity, it was reported that $\mathrm{SH}$ is associated with impairment of several exercise-related cardiopulmonary responses, resulting in some degree of exercise impairment (Kahaly, 2000).

Recently, a strong association between $\mathrm{SH}$ and atherosclerotic cardiovascular disease, independent of the traditional risk factors (i.e., hypercholesterolemia, hypertension, smoking, diabetes mellitus), was noted in a large cross-sectional survey of postmenopausal women (the Rotterdam Study) (Hak et al., 2000). Although the mechanism responsible for this association remains to be clarified, compelling evidence indicates that $\mathrm{SH}$ is associated with an atherogenic lipid profile, characterized by increased circulating levels of total and low-density cholesterol and increased levels of oxidized low-density lipoproteins (Duntas, 2002; Duntas et al., 2002). It has been reported that SH may affect the hemostatic profile, thereby promoting a hypercoagulable state (Müller et al., 2001). Moreover, a reduced endothelium-dependent, flow-mediated vasodilation, which is an early marker of atherosclerosis, has been reported in patients with SH (Lekakis et al., 1997).

Importantly, when SH patients are treated with L-T4, most metabolic and cardiovascular abnormalities improve or even normalize (Danese et al., 2000; Biondi et al., 2002c). However, whether patients with $\mathrm{SH}$ should be treated remains the subject of disagreement (Chu and Crapo, 2001; McDermott and Ridgway, 2001).

\section{Thyroid Function in Cardiovascular Disorders}

The relationship between thyroid status and the cardiovascular system is not unidirectional. A body of data indicates that acute and chronic cardiovascular disorders may alter the metabolism of thyroid hormone.

Within 4 hours after acute uncomplicated myocardial infarction, circulating T3 and T4 levels are reduced by about 20\% and 40\%, respectively (Franklyn et al., 1984). In patients with chronic heart failure, serum thyroid hormone concentration decreases and reverse-T3 increases, the magnitude of changes paralleling the degree of functional impairment as assessed by the New York Heart Association classification (Hamilton et al., 1990). In patients undergoing cardiopulmonary or coronary-aortic bypass surgery, circulating T3 levels fall significantly in the postoperative period (Holland et al., 1991; Klemperer et al., 1995; Bettendorf et al., 1997).

In this regard, several lines of evidence suggest that the altered thyroid status in patients with cardiovascular disorders could modify cardiac gene expression and contribute to impaired cardiac function (Klein and Ojamaa, 1998). In animals, a low serum concentration of $\mathrm{T} 3$ induced by caloric restriction was associated with impaired cardiac contractility and altered gene expression similar to that seen in experimental hypothyroidism, which normalized with replacement 
doses of T3 (Katzeff et al., 1997). Decreased expression of thyroid hormone nuclear receptor $\alpha-1$ associated with increased expression of the thyroid hormone nuclear receptor $\alpha$-2, typical of tissue hypothyroidism, recently was reported in myocardial biopsy from patients with chronic heart failure (Kinugawa et al., 2001). Of note, this abnormal pattern of thyroid hormone receptor expression was correlated with the reduced myocardial expression of the $\alpha$-isoform of myosin heavy chain and the increased expression of the $\beta$-isoform of myosin heavy chain and of the atrial natriuretic peptide, thereby implicating tissue thyroid status in the development of the failing heart phenotype (Kinugawa et al., 2001). In 23 patients with advanced chronic heart failure, a single intravenous dose of T3 elicited a significant hemodynamic improvement by reducing peripheral vascular resistance and increasing cardiac output (Hamilton et al., 1998). Treatment with low-dose L-T4 daily for 12 weeks greatly benefited 20 patients with chronic heart failure by reducing peripheral vascular resistance, increasing cardiac output, and improving exercise performance (Moruzzi et al., 1996). Moreover, in patients undergoing cardiopulmonary or coronary artery bypass surgery, intravenous treatment with T3 immediately before and/or after surgery significantly improved postoperative cardiac function and reduced somewhat the extent of surgical mortality (Klemperer et al., 1995; Cimochowski et al., 1997; Mullis-Janson et al., 1999; Bettendorf et al., 2000). In no instance did thyroid hormone treatment deteriorate cardiac function or induce myocardial ischemia rhythm disturbances or other untoward effects (Klemperer et al., 1995; Moruzzi et al., 1996; Cimochowski et al., 1997; Hamilton et al., 1998; Mullis-Janson et al., 1999; Bettendorf et al., 2000).

In line with these preliminary observations, studies with experimental models of LV dysfunction and preliminary clinical investigation of patients with chronic heart failure reported that the thyroid hormone analog 3,5-diiodothyropropionic acid, whose biological activity profile is similar to that of thyroid hormone except for effects on heart rate, elicited relevant hemodynamic improvements by reducing systemic vascular resistance and improving both systolic and diastolic LV function. This was accompanied by an increase in cardiac output and improved lipid profile (Morkin et al., 2002).

\section{Conclusion}

Thyroid dysfunction causes remarkable cardiovascular derangements. Because signs and symptoms referable to the cardiovascular system may be the only manifestations of overt thyroid dysfunction and because persistent subclinical thyroid dysfunction may notably increase the cardiovascular risk, thyroid status should be systematically investigated in all patients with newly diagnosed or worsening cardiovascular disease, especially the elderly. In addition, patients with acute or chronic cardiovascular disorders have abnormalities in peripheral 
thyroid hormone metabolism that may alter cardiac function. The finding that administration of thyroid hormone or its analog 3,5-diiodothyropropionic acid may greatly benefit these patients should foster further investigation in this area.

\section{ACKNOWLEDGMENT}

The authors thank Jean Ann Gilder for editing the text.

\section{REFERENCES}

Aber CP 1964 The heart in hypothyroidism. Am Heart J 68:428-430

Andersen S, Pedersen KM, Brunn NH, et al. 2002 Narrow individual variations in serum T4 and T3 in normal subjects: a clue to understanding of subclinical thyroid disease. J Clin Endocrinol Metab 87:1068-1072

Anthonisen P, Holst E, Thomsen AA 1960 Determination of cardiac output and other hemodynamic data in patients with hyper- and hypothyroidism, using dye dilution technique. Scand J Clin Lab Invest 12:472-480

Auer J, Scheibner P, Mische T, et al. 2001 Subclinical hyperthyroidism as a risk factor for atrial fibrillation. Am Heart J 142:838-842

Bengel FM, Nekolla SG, Ibrahim T, et al. 2000 Effect of thyroid hormones on cardiac function, geometry, and oxidative metabolism assessed noninvasively by positron emission tomography and magnetic resonance imaging. J Clin Endocrinol Metab 85:1822-1827

Bettendorf M, Schmidt KG, Tiefenbacher U, et al. 1997 Transient secondary hypothyroidism in children after cardiac surgery. Pediatr Res 41:375-379

Bettendorf M, Schmidt KG, Grulich-Henn J, et al. 2000 Tri-iodothyronine treatment in children after cardiac surgery: a double-blind, randomized, placebo-controlled study. Lancet 356:529_ 534

Bindels AJ, Westendorp RG, Frolich M, et al. 1999 The prevalence of subclinical hypothyroidism at different total plasma cholesterol levels in middle aged men and women: a need for case-finding? Clin Endocrinol 50:217-220

Biondi B, Fazio S, Carella C, et al. 1993 Cardiac effects of long-term thyrotropin-suppressive therapy with levothyroxine. J Clin Endocrinol Metab 77:334-337

Biondi B, Fazio S, Carella C, et al. 1994 Control of adrenergic overactivity by B-blockade improves quality of life in patients receiving long term suppressive therapy with levothyroxine. J Clin Endocrinol Metab 78:1028-1033

Biondi B, Fazio S, Cuocolo A, et al. 1996 Impaired cardiac reserve and exercise capacity in patients receiving long-term thyrotropin suppressive therapy with levothyroxine. J Clin Endocrinol Metab 81:4224-4228

Biondi B, Fazio S, Palmieri EA, et al. 1999a Left ventricular diastolic dysfunction in patients with subclinical hypothyroidism. J Clin Endocrinol Metab 84:2064-2067

Biondi B, Fazio S, Palmieri EA, et al. 1999b Effects of chronic subclinical hyperthyroidism on cardiac morphology and function. Cardiologia 44:443-449

Biondi B, Palmieri EA, Fazio S, et al. 2000 Endogenous subclinical hyperthyroidism affects quality of life and cardiac morphology and function in young and middle-aged patients. J Clin Endocrinol Metab 85:4702-4705

Biondi B, Palmieri EA, Lombardi G, et al. 2002a Effects of thyroid hormone on cardiac function: the relative importance of heart rate, loading conditions, and myocardial contractility in the 
regulation of cardiac performance in human hyperthyroidism. J Clin Endocrinol Metab 87:968-974

Biondi B, Fazio S, Palmieri EA, et al. 2002b Mortality in elderly patients with subclinical hyperthyroidism. Lancet 359:799-800

Biondi B, Palmieri EA, Lombardi G, et al. 2002c Effects of subclinical thyroid dysfunction on the heart. Ann Intern Med 137:904-914

Brent GA 1994 The molecular basis of thyroid hormone action. N Engl J Med 331:847-853

Brenta G, Mutti LA, Schnitman M, et al. 2003 Assessment of left ventricular diastolic function by radionuclide ventriculography at rest and exercise in subclinical hypothyroidism, and its response to L-thyroxine therapy. Am J Cardiol 2003 91:1327-1330

Cacciatori V, Bellavere F, Pezzarossa A, et al. 1996 Power spectral analysis of heart rate in hyperthyroidism. J Clin Endocrinol Metab 81:2828-2835

Canaris GJ, Manowitz NR, Mayor G, et al. 2000 The Colorado thyroid disease prevalence study. Arch Intern Med 160:526-534

Ching GW, Franklyn JA, Stallard TJ, et al. 1996 Cardiac hypertrophy as a result of long-term thyroxine therapy and thyrotoxicosis. Heart 75:363-368

Chu JW, Crapo LM 2001 The treatment of subclinical hypothyroidism is seldom necessary. J Clin Endocrinol Metab 86:4591-4599

Cimochowski GE, Harostock MD, Foldes PG 1997 Minimal operative mortality in patients undergoing coronary artery bypass with significant left ventricular dysfunction by maximization of metabolic and mechanical support. J Thorac Cardiovasc Surg 113:655-666

Crowley WF Jr, Ridgway EC, Bough EW, et al. 1977 Noninvasive evaluation of cardiac function in hypothyroidism. Response to gradual thyroxine replacement. N Engl J Med 296:1-6

Danese MD, Ladenson PW, Meinert CL, et al. 2000 Effect of thyroxine therapy on serum lipoproteins in patients with mild thyroid failure: a quantitative review of the literature. J Clin Endocrinol Metab 85:2993-3001

Davis PJ, Davis FB 1993 Acute cellular actions of thyroid hormone and myocardial function. Ann Thorac Surg 56(suppl):S16-S23

DeGroot WJ, Leonard JJ 1970 Hyperthyroidism as a high cardiac output state. Am Heart J 79:265-275

Dernellis J, Panaretou M 2002 Effects of thyroid replacement therapy on arterial blood pressure in patients with hypertension and hypothyroidism. Am Heart J 143:718-724

Di Bello V, Monzani F, Giorgi D, et al. 2002 Ultrasonic myocardial textural analysis in subclinical hypothyroidism. J Am Soc Echocardiogr 13:832-840

Dillmann WH 1990 Biochemical basis of thyroid hormone action in the heart. Am J Med $88: 626-630$

Duntas LH 2002 Thyroid disease and lipids. Thyroid 12:287-293

Duntas LH, Mantzou E, Koutras DA 2002 Circulating levels of oxidized low-density lipoprotein in overt and mild hypothyroidism. Thyroid 12:1003-1007

Endo T, Komiya I, Tsukui T, et al. 1979 Re-evaluation of a possible high incidence of hypertension in hypothyroid patients. Am Heart J 98:684-688

Everts ME, Verhoeven FA, Bezstarosti K, et al. 1996 Uptake of thyroid hormone in neonatal rat cardiac myocytes. Endocrinology 137:4235-4242

Faber J, Petersen L, Wiinberg N, et al. 2002 Hemodynamic changes after levothyroxine treatment in subclinical hypothyroidism. Thyroid 12:319-324

Fazio S, Biondi B, Carella C, et al. 1995 Diastolic dysfunction in patients on thyroid-stimulatinghormone suppressive therapy with levothyroxine: beneficial effect of $\beta$ blockade. J Clin Endocrinol Metab 80:2222-2226 
Feldman T, Borow KM, Sarne DH, et al. 1986 Myocardial mechanics in hyperthyroidism: importance of left ventricular loading conditions, heart rate and contractile state. J Am Coll Cardiol 7:967-974

Fletcher AK, Weetman AP 1998 Hypertension and hypothyroidism. J Hum Hypertens 12:79-82

Foldes J, Istvanfy M, Halmagyi H, et al. 1987 Hypothyroidism and the heart. Examination of left ventricular function in subclinical hypothyroidism. Acta Med Hung 44:337-347

Fommei E, Iervasi G 2002 The role of thyroid hormone in blood pressure homeostasis: evidence from short-term hypothyroidism in humans. J Clin Endocrinol Metab 87:1996-2000

Franklyn JA, Gammage MD, Ramsden DB, et al. 1984 Thyroid status in patients after acute myocardial infarction. Clin Sci (Lond) 67:585-590

Fredlund BO, Olsson SB 1983 Long QT interval and ventricular tachycardia of "torsade de pointe" type in hypothyroidism. Acta Med Scand 213:231-235

Friedman MJ, Okada RD, Ewy GA, et al. 1982 Left ventricular systolic and diastolic function in hyperthyroidism. Am Heart J 104:1303-1308

Gibson JG, Harris AW 1939 Clinical studies on the blood volume: V. Hyperthyroidism and myxedema. J Clin Invest 18:59-65

Gick GG, Melikian J, Ismail-Beigi F 1990 Thyroidal enhancement of rat myocardial Na,K-ATPase: preferential expression of alpha 2 activity and mRNA abundance. J Membr Biol 115:273-282

Gilligan DM, Ellenbogen KA, Epstein AE 1996 The management of atrial fibrillation. Am J Med 101:413-421

Graettinger JS, Muenster JJ, Selverstone LA, et al. 1959 A correlation of clinical and hemodynamic studies in patients with hyperthyroidism with and without congestive heart failure. J Clin Invest 39:1316-1327

Greenland P, Daviglus ML, Dyer AR, et al. 1999 Resting heart rate is a risk factor for cardiovascular and noncardiovascular mortality: the Chicago Heart Association Detection Project in Industry. Am J Epidemiol 149:853-862

Haider AW, Larson MG, Benjamin EJ, et al. 1998 Increased left ventricular mass and hypertrophy are associated with increased risk for sudden death. J Am Coll Cardiol 32:1454-1459

Hak AE, Pols HAP, Visser TJ, et al. 2000 Subclinical hypothyroidism is an independent risk factor for atherosclerosis and myocardial infarction in elderly women: the Rotterdam Study. Ann Intern Med 132:270-278

Hamilton MA, Stevenson LW, Luu M, et al. 1990 Altered thyroid hormone metabolism in advanced heart failure. J Am Coll Cardiol 16:91-95

Hamilton MA, Stevenson LW, Fonarow GC, et al. 1998 Safety and hemodynamic effects of intravenous triiodothyronine in advanced congestive heart failure. Am J Cardiol 81:443-447

Hoit BD, Khoury SF, Shao Y, et al. 1997 Effects of thyroid hormone on cardiac beta-adrenergic responsiveness in conscious baboons. Circulation 96:592-598

Holland FW II, Brown PS Jr, Weintraub BD, et al. 1991 Cardiopulmonary bypass and thyroid function: a "euthyroid sick syndrome." Ann Thorac Surg 52:46-50

Huber G, Staub JJ, Meier C, et al. 2002 Prospective study of the spontaneous course of subclinical hypothyroidism: prognostic value of thyrotropin, thyroid reserve, and thyroid antibodies. J Clin Endocrinol Metab 87:3221-3226

Kahaly GJ 2000 Cardiovascular and atherogenic aspects of subclinical hypothyroidism. Thyroid 10:665-679

Kahaly GJ, Nieswandt J, Wagner S, et al. 1998 Ineffective cardiorespiratory function in hyperthyroidism. J Clin Endocrinol Metab 83:4075-4078

Kahaly GJ, Wagner S, Nieswandt J, et al. 1999 Stress echocardiography in hyperthyroidism. J Clin Endocrinol Metab 84:2308-2313

Katzeff HL, Powell SR, Ojamaa K 1997 Alteration in cardiac contractility and gene expression during low-T3 syndrome: prevention with T3. Am J Physiol 273:E951-E956 
Keating FR, Parkin TW, Selby JB, et al. 1960 Treatment of heart disease associated with myxedema. Prog Cardiovasc Dis 3:364-381

Kinugawa K, Minobe WA, Wood WM, et al. 2001 Signaling pathways responsible for fetal gene induction in the failing human heart: evidence for altered thyroid hormone receptor gene expression. Circulation 103:1089-1094

Kiss E, Jakab G, Kranias EG, et al. 1994 Thyroid hormone induced alteration in phospholamban protein expression: regulatory effects on sarcoplasmic reticulum $\mathrm{Ca} 2+$ transport and myocardial relaxation. Circ Res 75:245-251

Kiss E, Brittsan AG, Elds I, et al. 1998 Thyroid hormone-induced alterations in phospholambandeficient mouse hearts. Circ Res 83:608-613

Klein I 1988 Thyroxine-induced cardiac hypertrophy: time course of development and inhibition by propanolol. Endocrinology 123:203-210

Klein I 1989 Thyroid hormone and high blood pressure. In: Laragh JH, Brenner BM, Kaplan NM, eds. Endocrine Mechanisms in Hypertension, vol. 2. New York: Raven Press; 61-80

Klein I, Levey GS 1984 Unusual manifestations of hypothyroidism. Arch Intern Med 144:123-128

Klein I, Ojamaa K 1998 Thyroid hormone treatment of congestive heart failure. Am J Cardiol $81: 490-491$

Klein I, Ojamaa K 2000 The cardiovascular system in hypothyroidism. In: Braverman LE, Utiger RD, eds. Werner \& Ingbar's The Thyroid: A Fundamental and Clinical Text, edit. 8. Philadelphia: Lippincott Williams \& Wilkins; 777-782

Klein I, Ojamaa K 2001 Thyroid hormone and the cardiovascular system. N Engl J Med 344:501-509

Klemperer JD, Klein I, Gomez M, et al. 1995 Thyroid hormone treatment after coronary-artery bypass surgery. N Engl J Med 333:1522-1527

Ladenson PW 1993 Thyrotoxicosis and heart: something old and something new. J Clin Endocrinol Metab 77:332-333

Ladenson PW, Sherman SI, Boughman RL, et al. 1992 Reversible alterations in myocardial gene expression in a young man with dilated cardiomyopathy and hypothyroidism. Proc Natl Acad Sci USA 89:5251-5255

Lekakis J, Papamichael C, Alevizaki M, et al. 1997 Flow-mediated, endothelium-dependent vasodilatation is impaired in subjects with hypothyroidism, borderline hypothyroidism, and high-normal serum thyrotropin (TSH) values. Thyroid 7:411-414

Levey GS, Klein I 1990 Catecholamine-thyroid hormone interactions and the cardiovascular manifestations of hyperthyroidism. Am J Med 88:642-646

Lewis BS, Ehrenfeld EN, Lewis N, et al. 1979 Echocardiographic LV function in thyrotoxicosis. Am Heart J 97:460-468

Luboshitzky R, Aviv A, Herer P, et al. 2002 Risk factors for cardiovascular disease in women with subclinical hypothyroidism. Thyroid 12:421-425

Magner J, Clark W, Allenby P 1988 Congestive heart failure and sudden death in a young woman with thyrotoxicosis. West J Med 110:759-760

McAllister RM, Delp MD, Loughlin MH 1995 Thyroid status and exercise tolerance. Cardiovascular and metabolic consideration. Sport Med 20:189-198

McDermott MT, Ridgway EC 2001 Subclinical hypothyroidism is mild thyroid failure and should be treated. J Clin Endocrinol Metab 86:4585-4590

McDermott MM, Feinglass J, Sy J, et al. 1995 Hospitalized congestive heart failure patients with preserved versus abnormal left ventricular systolic function: clinical characteristics and drug therapy. Am J Med 99:629-635

Mercuro G, Panzuto MG, Bina A, et al. 2000 Cardiac function, physical exercise capacity, and quality of life during long-term thyrotropin-suppressive therapy with levothyroxine: effect of individual dose tailoring. J Clin Endocrinol Metab 85:159-164 
Merillon JP, Passa P, Chastre J, et al. 1981 Left ventricular function and hyperthyroidism. Br Heart J 46:137-143

Mintz G, Pizzarello R, Klein I 1991 Enhanced left ventricular diastolic function in hyperthyroidism: noninvasive assessment and response to treatment. J Clin Endocrinol Metab 73:146-150

Monzani F, Di Bello V, Caraccio N, et al. 2001 Effects of levo-thyroxine on cardiac function and structure in subclinical hypothyroidism: a double blind, placebo-controlled study. J Clin Endocrinol Metab 86:1110-1115

Morkin E 1993 Regulation of myosin heavy chain genes in the heart. Circulation 87:1451-1460

Morkin E, Pennock GD, Spooner PH, et al. 2002 Clinical and experimental studies on the use of 3,5-diiodothyropropionic acid, a thyroid hormone analogue, in heart failure. Thyroid 12:527533

Moruzzi P, Doria E, Agostoni PG 1996 Medium-term effectiveness of L-thyroxine treatment in idiopathic dilated cardiomyopathy. Am J Med 101:461-467

Müller B, Tsakiris DA, Roth CB, et al. 2001 Haemostatic profile in hypothyroidism as potential risk factor for vascular or thrombotic disease. Eur J Clin Invest 31:131-137

Mullis-Janson SL, Argenziano M, Corwin S, et al. 1999 A randomized double-blind study of the effect of triiodothyronine on cardiac function and morbidity after coronary bypass surgery. J Thorac Cardiovasc Surg 117:1128-1134

Nakazawa HK, Sakurai K, Humada N, et al. 1982 Management of atrial fibrillation in the post-thyrotoxic state. Am J Med 72:903-906

Napoli R, Biondi B, Guardasole V, et al. 2001 Impact of hyperthyroidism and its correction on vascular reactivity in humans. Circulation 104:3076-3080

Nordyke RA, Gilbert FI Jr, Harada AS 1988 Graves' disease. Influence of age on clinical findings. Arch Intern Med 148:626-631

Obuobie K, Smith J, Evans LM, et al. 2002 Increased central arterial stiffness in hypothyroidism. J Clin Endocrinol Metab 87:4662-4666

Ojamaa K, Klemperer JD, Klein I 1996a Acute effects of thyroid hormone on vascular smooth muscle. Thyroid 6:505-512

Ojamaa K, Klemperer JD, MacGilvray SS, et al. 1996b Thyroid hormone and hemodynamic regulation of beta-myosin heavy chain promoter in the heart. Endocrinology 137:802-808

Ojamaa K, Sabet A, Kenessey A, Shenoy R, et al. 1999 Regulation of rat cardiac Kv1.5 gene expression by thyroid hormone is rapid and chamber specific. Endocrinology 140:3170-3176

Ojamaa K, Klein I, Sabet A, Steinberg SF 2000 Changes in adenylyl cyclase isoforms as a mechanism for thyroid hormone modulation of cardiac beta-adrenergic receptor responsiveness. Metabolism 49:275-279

Ojamaa K, Kenessey A, Klein I 2002 Thyroid hormone regulation of phospholamban phosphorylation in the rat heart. Endocrinology 141:2139-2144

Park KW, Dai HB, Ojamaa K, et al. 1997 The direct vasomotor effect of thyroid hormones on rat skeletal muscle resistance arteries. Anesth Analg 85:734-738

Parle JV, Maisonneuve P, Sheppard MC, et al. 2001 Prediction of all-cause and cardiovascular mortality in elderly people from one low serum thyrotropin result: a 10-year cohort study. Lancet 358:861-865

Petersen P, Hansen JM 1988 Stroke in thyrotoxicosis with atrial fibrillation. Stroke 19:15-18

Resnick LM, Laragh JH 1982 Plasma renin activity in syndromes of thyroid hormone excess and deficiency. Life Sci 30:585-586

Saito I, Ito K, Saruta T 1983 Hypothyroidism as a cause of hypertension. Hypertension 5:112-115

Sawin CT, Geller A, Wolf PA, et al. 1994 Low serum thyrotropin concentrations as a risk factor for atrial fibrillation in older persons. N Engl J Med 331:1249-1252 
Shapiro LE, Sievert R, Ong L, et al. 1997 Minimal cardiac effects in asymptomatic athyreotic patients chronically treated with thyrotropin-suppressive doses of L-thyroxine. J Clin Endocrinol Metab 82:2592-2595

Streeten DH, Anderson GH Jr, Howland T, et al. 1988 Effects of thyroid function on blood pressure. Recognition of hypothyroid hypertension. Hypertension 11:78-83

Sun ZQ, Ojamaa K, Nakamura TY, et al. 2001 Thyroid hormone increases pacemaker activity in rat neonatal atrial myocytes. J Mol Cell Cardiol 33:811-824

Theilen EO, Wilson WR 1967 Hemodynamic effects of peripheral vasoconstriction in normal and thyrotoxic subjects. J Appl Physiol 22:207-210

Tunbridge WMG, Evered DC, Hall R, et al. 1977 The spectrum of thyroid disease in a community: the Whickham survey. Clin Endocrinol (Oxf) 7:481-493

Vanderpump MP, Tunbridge WM, French JM, et al. 1995 The incidence of thyroid disease in the community: a twenty-year follow-up of the Whickham Survey. Clin Endocrinol 43:55-69

Vitale G, Galderisi M, Lupoli GA, et al. 2002 Left ventricular myocardial impairment in subclinical hypothyroidism assessed by a new ultrasound tool: pulsed tissue Doppler. J Clin Endocrinol Metab 87:4350-4355

von Olshausen K, Bischoff S, Kahaly G, et al. 1989 Cardiac arrhythmias and heart rate in hyperthyroidism. Am J Cardiol 63:930-933

Walker JD, Crawford FA, Kato S, et al. 1994 The novel effects of 3,5,3'-triiodo-L-thyronine on myocyte contractile function and beta-adrenergic responsiveness in dilated cardiomyopathy. J Thorac Cardiovasc Surg 108:672-679

Wieshammer S, Keck FS, Waitzinger J, et al. 1989 Acute hypothyroidism slows the rate of left ventricular diastolic relaxation. Can J Physiol Pharmacol 67:1007-1010 